\title{
16
}

\section{TONE FROM THE TOP}

\author{
Sir John Parker
}

The organisational "tone from the top" is driven by the integrity, honesty, and professionalism of the leadership team and each board member. The board must set the remit and drumbeat for the behavioural expectations of directors and management, and it is important that every individual consistently lives out the organisation's values in their interface with all stakeholders.

It should not be forgotten that it is a privilege to serve in a boardroom large or small. It is also a great honour to be chosen to lead; to lead teams, to lead companies, to develop them, and to get the best out of them. It took me some time on my boardroom journey to fully appreciate the extent to which the leader can really influence and shape events and the future. As the leaders of today and of tomorrow, you should never underestimate the power you have to change things for the better.

\section{Leadership in corporate life}

From early days in management, I was also taught that in each leadership role performed, one should endeavour to always "leave things better DOI: $10.4324 / 9781003201182-19$ 
than you found them." I was also taught to believe in "deeds not words." We who have the privilege of leadership must take ownership - and the responsibility and authority that go with it.

- Do you take ownership for the board's collective and individual actions?

- Do you lead confidently with integrity and honesty, communicating clearly your expectations and the unambiguous goals you want all of your team to aim for whilst avoiding intensity?

- Do you as the leader also have some fun and not neglect the power of good humour?

- Have you learnt the difference between being liked and being respected, and do you worry about the things you can really influence and not about those you can't?

- Do you leave your ego at home?

Whatever leadership role you find yourself in, it will be one of constant discovery about your own capabilities and potential and about the potential of the people you work with. All good leaders are on a journey, inspiring, building, and developing their teams as they go. However, it can also be a lonely place where you can feel isolated and alone.

- Do you demonstrate courage and calmness when faced with a very tough situation, especially one that has arisen without any warning?

- Do you exude a quiet confidence that "you can find the way through crises" - if all the team will rally around and give their support?

I came to the conclusion in my early days as a leader that you must never lie awake - since you can't solve much in the middle of the night and if you don't get your sleep you'll not be fit to handle tomorrow's challenges.

- Have you as leader learned to relax, set work aside, and get time for mental refreshment?

- Have you found your ideal work-life balance?

In the midst of tough challenges, you can be sure you will get a new perspective from resting the mind and giving it something entirely different to think about. All work and no play or no renewal of the soul is not good for 
us human beings. There are so many lessons to learn about leadership and having a balance in life. There is no point wrestling with a difficult issue for 24 hours in the day - you need to find a work-life balance.

\section{Quality leadership}

The word "leader" comes from a root meaning a path, a roadway or the course of a ship at sea, and quality leadership is critical to the success of any organisation. It is critically important in the boardroom, which creates the drumbeat for the executive and sets the tone for all that an organisation stands for as well as all that it aims to do for its shareholders, its employees, and the communities in which it operates.

The greatest bulwark against the destruction of shareholder value is a high-quality board comprising a wide bandwidth of skills and experience. I take considerable care and derive great satisfaction from building quality boards that create a professional openness and culture of transparency and respect to challenge. You can get such wise collective advice and steerage from a highly professional board team. We all need to be reminded that "None of us are as smart as all of us." As chairmen, we must also seek constant improvement in all our board management and administrative processes with the aim of keeping at the forefront of best boardroom practice.

- Does the board take ownership of the strategy, debate, and stress test it?

- Does the board empower the CEO and the executive to execute it and deliver the strategy?

- $\quad$ Does the board hold management accountable for the strategy?

Leadership is vitally important in the $\mathrm{CEO}$ and in each executive director. Together they release the day-to-day energy and direction into the business. They see to it that the board decisions, not only on strategy but on major policy, are implemented and together with management, they lead the organisation on the "journey" to be the best and to be at the forefront. As a chairman, your most important task is to ensure the company is led by a quality $\mathrm{CEO}$. 


\section{Restless leaders}

Some readers will be familiar with the Japanese word "kaizen." It captures the philosophy of constant improvement. Leaders need to be "restless" in seeking out ways to do things "better tomorrow than we did them today." The journey of constant improvement, leaving things better than we found them, to be the best, has to be at the heart of leadership thinking. Great human talent is what makes great companies.

- Do you ensure that you and your key people are developed to the maximum of their potential?

All of you as leaders are unique as individuals. You are, in fact, a special individual with the capacity to achieve great things. And so you need to work to ensure you develop to the maximum of your potential - you, as an individual leader, need to seek to discover your inner strengths and perform at exceptional levels. But many leaders, many managers, like many people, never exploit their unique abilities or discover their true potential as a leader.

Finally, here are some further characteristics that over the years I have come to associate with a good organisational leader:

Do you communicate effectively the board's agreed strategy?

It is critical when the strategy and the overall plan is agreed for the leader to gain the commitment of the management team and employees by layers of continuous communication. You need to set out to grab the attention of the people.

Do you have the ability to inspire and build up the team to believe in the plan and to be confident about its execution?

The leader must be visible, let people make some mistakes, but be there to give support and guidance when required. He or she is there to make people feel warm and confident and part of a great team and company.

Do you empower your people, giving them clear authority with welldefined responsibilities? 
The good leader holds people accountable for delivery, rewards, and celebrates success with them. I am sure you will agree that part of the thrill of leadership is to see others, either as individuals or as a team, grow and master something they have not achieved before.

Do you listen and learn?

Listening with great care is a respectful thing to do with colleagues. It is not only valuable, it's vital.

Are you decisive?

"Paralysis through analysis" can be a disastrous trait.

Are you courageous and do you sometimes rely on instinct?

Sometimes as a leader you are confronted with the totally unexpected there is no time to study options - you are faced with making an instant decision and you will have to rely on innate good judgement and on your instinctive feel for what is right. So there are times when you must act without too much analysis, based on instinct and gut feel. Certain unexpected events call for decisive action within a short window of time.

Finally, are you consistent in your behaviour - do you live out your words? As our American cousins would say, "Do you walk the talk"?

Do not as a leader sign up to behavioural codes or value statements if you are not going to be consistent. I can think of no greater risk to a leader's credibility than not living out these words. 